\title{
O lacre da memória: o arquivo sensível de Aurora Rodrigues e a resistência à ditadura portuguesa ${ }^{1}$
}

\section{The memory seal: Aurora Rodrigues' sensitive archive and resistance to the Portuguese dictatorship}

Enviado em: 30/09/2020

Aceito em: 05/01/2021

Paula Godinho ${ }^{2}$

\begin{abstract}
Há esta importância das coisas pequeninas, que percebi bem pela primeira vez. Hoje, quando conto, até sinto às vezes uma espécie de pudor. São as coisas mesmo muito pequenas que nos aguentam. Isto era tudo muito pequeno, mas era o que fazia de mim uma pessoa livre. Falava, dizia e pensava. Há uma coisa que fui forçada a viver, mas que me deu a consciência da força e do poder que efectivamente temos em todas as circunstâncias. Podemos resistir e é, no fundo, este sentimento que foi amplificado e se materializou nas pequenas coisas.
\end{abstract}

Aurora Rodrigues, Gente comum - Uma História na PIDE

\section{Resumo}

Neste artigo proponho uma reflexão a partir dos materiais produzidos e recebidos na prisão por uma prisioneira política maoista durante os anos finais da longa ditadura portuguesa (1926-1974). Através deles, com base na partilha do sensível, segundo a proposta de Jacques Rancière, acede-se ao conhecimento da experiência de resistência, assente nas suas memórias traumáticas. As memórias coletivas sensíveis, construtoras de sentidos de pertença, estão ligadas aos grupos, refletindo lugares sociais e perspetivas diferenciadas. Mercê de conjunturas determinadas, algumas podem ultrapassar as dimensões do grupo e implantarem-se como memórias da sociedade. Na linha de Rancière, a partilha do sensível, essa inscrição da ordem do mundo nas categorias do visível e do dizível - o que se pode ver e o que é invisível, o se ouve ou é mero ruído -, é interditada quando se recusa a ordem da dominação e a negação sensível de um mundo comum.

Palavras- chave: Ditadura; Portugal, Resistência, Partilha do sensível.

1 - Uma primeira versão deste texto foi publicada em 2017 em francês. Denominou-se então "La résistance à la dictature portugaise et le sceau de la mémoire: l'archive sensible d'Aurora Rodrigues", in Maria-BeneditaBasto e David Marcilhacy, dir. L'archivesensible :mémoires, intimitéetdomination, Paris, EditionsHispaniques :155-170. Agradeço a autorização de publicação em português. Estou grata a Inês Godinho pela leitura crítica, a revisão e as sugestões.

2 - Paula Godinho (PhD Antropologia, FCSH-NOVA), investigadora IHC-NOVA e professora associada com agregação no Departamento de Antropologia da FCSH-Universidade Nova de Lisboa. Fundadora da Red(e) Ibero-Americana Resistência e/y Memória e membro do grupo de trabalho CLACSO "Izquierdas: praxis y transformación social" (2019-2022). Prémio XesúsTaboadaChivite, 2008 (Galiza, Espanha), Xuíza honorária pela Associación de Amigos do Couto Mixto, Galiza, 2011, Arraiana Maior pela Associación Arraianos (Galiza, 2017). Vários anos de trabalho de campo em Portugal, na fronteira, na Galiza, no Brasil, sobre reprodução social, festas e rituais, resistência e movimentos sociais, usos políticos da memória e práticas do património, processos de emblematização, turistificação e mercantilização da cultura, topografias do poder, culturas de fronteira e nacionalismos de diáspora. 


\begin{abstract}
In this article I propose a reflection from the materials produced and received in prison by a Maoist political prisoner during the final years of the long Portuguese dictatorship (1926-1974). Through these materials, based on the «partage du sensible», according to Jacques Rancière's proposal, we can access to knowledge of the experience of resistance, based on Aurora Rodrigues's traumatic memories. Sensitive collective memories, which build a sense of belonging, are linked to groups, reflecting social places and different perspectives. Due to certain circumstances, some may go beyond the dimensions of the group and establish themselves as social memories. In Rancière's perspective, the sharing of the sensitive, this inscription of the order of the world in the categories of what can be seen and what is invisible, what is heard or is mere noise, is prohibited when the people refuses the order of domination and the sensitive negation of a common world.
\end{abstract}

Keywords: Dictatorship; Portugal; Resistance; Partage du sensible.

\title{
Memória íntima na ditadura portuguesa
}

Num postal endossado à filha e enviado para a cadeia de Caxias em 8 de Junho de 1973, António Rodrigues escreve:

\begin{abstract}
"Querida Filha
Votos sinceros para que estejas de boa saúde, nós vamos como Deus quer

Estranho as tuas notícias, estou aflito sem se escrever ao menos um postal, até penso que não tenhas sido tu que não tenhas escrito, pois não é hábito, serão as cartas que se terão extraviado. Está comigo a avó devido ao meu estado de saúde, e teve de deixar o avô naquele estado. Tua mãe há uma semana que está em Lisboa e vai todos os dias à cadeia para te visitar e não é autorizada, não sei porquê, não julgava que essas coisas pudessem fazer-se a uma mãe, que é o nome mais sagrado do mundo. Pedimos a Deus, que Deus não abandona ninguém. Não sei que tenhas feito de tão mau, pois não o dizes. Um abraço de teu pai."
\end{abstract}

Trata-se do pai de Aurora Rodrigues, presa pela PIDE-DGS no dia 3 de maio de 1973 e enviada para um dos presídios políticos da ditadura portuguesa (1926 -1974). Aurora foi sujeita a longas sessões de tortura, com privação do sono (durante 16 dias), espancamentos, tentativas de afogamento e humilhações várias, e só 38 anos depois contaria a sua história (Rodrigues, 2011).

O homem que escreve, destroçado por uma depressão e inquieto pelas sevícias que a sua filha estaria presumivelmente a passar, dá-lhe a medida da sua preocupação. Todavia, sabe que o postal é lido antes pelos algozes e a principal mensagem é para eles. Ficam assim a saber que Aurora não está só: há uma família e uma rede social que inquirem e desconfiam das desculpas que lhes dão os carcereiros 
quando não permitem visitas. Não se conhece devoção religiosa a este alentejano, que fora mineiro e é então cantoneiro. A inocente referência a Deus, que «não abandona ninguém», é um sábio recurso para melhor ser lido pelo censor, que expurgava diariamente a correspondência destinada aos presos.

São muitas as cartas e postais do arquivo pessoal de Aurora Rodrigues recebidos na cadeia. A irmã, a mãe e o pai escreviam com regularidade pendular, dando novidades de casa, referindo os quotidianos da família e seus rearranjos devido à sua prisão, reportando as «saudades» das vizinhas e vizinhos, dos tios e restantes parentes, dos amigos. A irmã fala-lhe da sobrinha e das suas graças infantis, do carro novo, das rotinas em Serpa e das tentativas baldadas de visita no presídio de Caxias. A mãe escreve por vezes a partir do quintal, fala-lhe das flores que estão belas - os amores-perfeitos que levava à sua filha e que os carcereiros maceravam, impedindo que chegassem frescos -, das vizinhas do lado que mandam beijos e das sucessivas idas a Caxias, a partir do Alentejo, sem conseguir ver a sua filha.

É o último ano do longo fascismo português. Aurora Rodrigues tem então 21 anos e estuda na Faculdade de Direito. Presa pela polícia política portuguesa numa concentração de estudantes frente à Faculdade de Letras da Universidade de Lisboa, sofreu na cadeia o indizível, que o seu pai pressentia neste postal, pois conhecia os métodos da polícia política portuguesa. Aurora nascera no Alentejo, terra de latifúndio, com constantes lutas rurais pela melhoria das condições de vida, causticada violentamente pela repressão da ditadura e do Estado Novo (1926-1974).

Neste texto trabalha-se material sensível. Tendo participado na recolha, transcrição e organização da narração de vida de Aurora Rodrigues, proponho uma reflexão a partir dos materiais produzidos e recebidos na prisão que permitem aceder ao conhecimento da experiência de resistência, assente nas memórias traumáticas da jovem militante maoista, em Portugal, no final da ditadura. Em LePartagedusensible, Jacques Rancière recorda-nos que existe um sistema de evidências sensíveis que cria uma noção de comum, ao mesmo tempo que se detetam formas exclusivas e grupais, com cortes no tempo e no espaço, no que se torna visível e no que é invisível, na destrinça entre palavra e ruído (RANCIĖRE, 2000). Essa partilha do sensível, essa inscrição da ordem do mundo nas categorias do visível e do dizível - o que se pode ver e o que é invisível, o se ouve ou é mero ruído - é interditada quando se recusa a ordem da dominação, através da negação sensível de um mundo comum. Esse «comum» constitui um idioma coletivo, é também um formato assumido pela resistência, uma arma dos grupos subalternos e dos perseguidos, em conjunturas 
determinadas. Nota James C. Scott que quanto mais insidioso é o poder, tanto mais compacta tem de ser a camuflagem, através do discurso oculto e das regras de clandestinidade, acompanhados por modalidades de exposição excecional e intrépida. Conquanto se reporte a tempos de forte repressão, enfatiza-se neste texto a concomitante resistência, seja trivial e invisível, como arma dos fracos, ou adotando um formato visível, que confere aura aos que se expõem (SCOTT 1985, 1990).

Em resultado de uma dialética entre passado e presente, a memória vai tendo configurações distintas que se ajustam às alterações políticas, económicas e sociais. A longa privatização de memórias conduz a uma erosão do seu aspeto social, condenando ao presentismo (HARTOG, 2013). A memória coletiva, associada a determinados quadros sociais que têm uma idêntica visão sobre o passado, pode coexistir em paralelo com as versões oficiais e hegemónicas ${ }^{3}$. Reporta-se aos grupos em que cada indivíduo se enraíza. Alguns, vencidos no projeto delineado e que não se identificam com a perspetiva triunfante, refazem ucronicamente o que podia ter sido. Devido aos formatos revisionistas, os usos públicos da história podem não servir para que neles se revejam os elementos de vários grupos. Neste texto perfilha-se uma abordagem de proximidade, associada a um relato de cadeia por razões políticas e a um conjunto de documentos pessoais, ou produzidos pelos grupos que Aurora Rodrigues interseta, como a família e os camaradas que a acompanham. Argumentase que estabelecer o que pode ser dito e os limites do não partilhável robustece o sentido de comum, que constrói e mantém os grupos, ao mesmo tempo que confere ânimo aos seus que se encontram em situação difícil. Assim, os indivíduos escapam à diluição e às visões hegemónicas, reiterando sentimentos de pertença: as "massas" não existem, são uma abordagem exterior que subentende a alteridade, como demonstrou Raymond Williams ${ }^{4}$.

3 - Sobre a memóriacoletiva, ver os textosseminais de Maurice Halbwachs, M. Les Cadres Sociaux de la Mémoire, Paris, Albin Michel, com posfácio de G. Namer, 1994 (1925) e La Mémoire Collective, Paris, PUF, com prefácio de J. Duvignaud, 1968 (1950);também P. Nora "Entre Mémoire et Histoire" in Pierre Nora (dir.) Les Lieux de Mémoire - La République I, Paris, Gallimard, pp. X- XLII, 1988. Sobre os usos políticos da memória e os revisionismos ver, entre muitos outros, os textos da obra coordenada por M. Loffet al. (ed) Ditaduras e Revolução - Democracia e políticas da memória, Coimbra, Almedina, 2015. Para a noção de passadoutilizável, C. Iordachi e B. Trencsènyi, "In Search of a Usable Past: The question of National Identity in Romanian Studies, 1990-2000", East European Politics and Societies, vol. 17 (3), 2003:415-453.

4 - Escreve Raymond Williams que "[p]ara outras pessoas, nós somos as massas. As massassãooutraspessoas" in R. Williams, Culture and Society, London, The Hogarth Press, 1982[1958]:300, trad. minha). Como reafirmaria num outro texto, não existem massas, mas tão só maneiras de ver as pessoas como tal: a chusma, a multidão, remete sempre para os outros, os desconhecidos, a populaça, que é diferente de cada um. Ver R. Williams, Historia y culturacomun, Madrid, Catarata. 2008:50-51. 
Na procura de um sujeito sensível, os materiais utilizados contrariam a visão de que a escrita é uma mera reconstrução da verdade, ou o exclusivo domínio do investigador. Conquanto a análise seja exclusivamente minha, este texto resulta da cumplicidade com quem relatou - que reviu depois o seu relato e disponibilizou materiais do seu arquivo pessoal -,com uma perspetiva que reforça o papel das pessoas e obsta ao monopólio académico do conhecimento. Nesta abordagem de proximidade, entende-se num nível íntimo a influência da socialização primária no comportamento político, o papel das redes sociais no recrutamento partidário, 0 carácter do estímulo que motiva os indivíduos para o envolvimento político, as sucessivas mudanças na perceção da realidade que dependem do enquadramento num dado movimento e o impacto de um acontecimento na vida pessoal e no futuro ${ }^{5}$.

Num dia ainda quente do Outono de 2009, Aurora Rodrigues, antiga presa política, António Monteiro Cardoso e eu encontrámo-nos pela primeira vez para este projeto $^{6}$. A Aurora conheceu as masmorras de Caxias em duas ocasiões, antes e depois do 25 de Abril. Centrar-me-ei na sua primeira prisão, em 1973, em que foi isolada, espancada e sujeita à privação do sono durante 450 horas.

Aurora trouxe consigo um envelope com fotos, cartas, postais, um bloco quadriculado e recortes de jornal ${ }^{7}$. Uma vida contada não tem um princípio obrigatório nem um final conhecido. O seu testemunho enquadra uma narração de tipo autobiográfico dirigida para um período preciso da vida, que desencadeou emoções fortes, com um efeito pós-traumático a provocar sofrimento acrescido. A angústia que acompanhou os dias a seguir ao relato, depois de uma memória tão dolorosa, retida durante 38 anos, denunciou os efeitos a longo prazo da exposição a condições prisionais e de tortura, com a invenção de rotinas nas mais tremendas circunstâncias.

As utilizações da memória requerem uma aproximação teórico-metodológica que hibridize várias disciplinas, com uma perspetiva sobre a construção social da rememoração, a memória coletiva e a eventual construção de culturas de resistência

5 - Segue-se D. Della PORTA, "Life histories in the Analysis of Social Movements activists", in M. Diani e R. Eyerman, ed. Studying Collective Movements, London: 168-193. VertambémA.Portelli "Uchronic dreams: working class memory and possible worlds", Oral History, vol. 16, Outono, 1998: 46-56; A. Confino "Collective Memory and Cultural History: Problems of Method", The American HistoricalReview, vol. 102, n 5, Dec., 1997: 1386-1403; CRANE, S. "Writing the Individual back into Collective memory", The American Historical Review, vol. 102, n 5, 1997:1372-1385.

6 - António Monteiro Cardoso, historiador, é seu amigo desde os tempos da Faculdade de Direito de Lisboa. Foram camaradas em várias lutas, e militantes do MRPP desde o início da década de 1970 e por vários anos. Entre 1976 e 1985, também fui militante da FEM-L e do Partido Comunista dos Trabalhadores Portugueses (PCTP), criado pelo MRPP em 1976, não me cruzando então com Aurora, que só vira uma vez, em Abril de 2009.

7 - A recolha do relato foi feita em três longas sessões principais, complementadas por outras, por um encontro na Torre do Tombo, por um jantar, múltiplos telefonemas e envio de correio eletrónico. 
(GODINHO, 2001). O testemunho oral permite olhar para a história com os olhos dos que foram subalternizados, ou que provêm de grupos sociais subordinados e/ou perseguidos. No caso das ditaduras, o material de arquivo das polícias políticas desumaniza os resistentes, em autos que obnubilam a tortura a que estavam sujeitos e ocultam a fragilidade das pessoas, à mercê de condições incontroladas e cruéis. Através da perceção do sofrimento dos seres humanos, ouve-se o murmúrio das sociedades de que são o motor, a que dão o ritmo essencial e alimentador da realidade social. Enquanto a história se vai construindo a partir do exterior das representações que os indivíduos fazem, é importante proceder à avaliação da perspetiva sensível que estes próprios têm de si e de um conjunto de acontecimentos demarcados, numa sequência temporal precisa (GODINHO, 2011). No relato de Aurora Rodrigues entrelaça-se a história social e o retrato parcelar, obtido num segmento duma narração de vida, complementado com documentos pessoais e com a consulta de arquivos.

\section{Contexto: tempos e lugares}

A última década do Estado Novo em Portugal ficou marcada pelo crescendo das organizações políticas à esquerda do $\mathrm{PCP}^{8}$. Os maoistas viriam a corroborar a fragmentação da resistência, com posições distintas quanto à guerra colonial e tendo a revolução chinesa como pedra de toque ${ }^{9}$. Ganharia impacto público o Movimento Reorganizativo do Partido do Proletariado (MRPP), devido à ação ousada dos seus jovens militantes. Provinham do mundo estudantil, sobretudo da Faculdade de Direito e do ISCEF, bem como de uma zona operária da cintura de Lisboa ${ }^{10}$. Organizavam

8 - Como nota Miguel Cardina, "As décadas de sessenta e setenta assistiram à chegada de uma nebulosa de militâncias inequivocamente colocadas à esquerda. Os novos andamentos contestatários recusavam as supremacias geopolíticas oriundas do pós-guerra ao mesmo tempo que estimulavam - e eram estimulados - pelas grandes mutações sociais, culturais e morais que atravessavam a época. Um notório jogo de semelhanças agrupava esse feixe plural, suportado na crítica aos partidos comunistas tradicionais, na activação de um internacionalismo de novas cores e na tentativa de alargamento do "político» a domínios considerados pouco antes como exclusivamente privados." M. Cardina, A Esquerda Radical, Coimbra, AngelusNovus, 2010:7.

9"Não obstante esta dispersão por várias organizações, a corrente marxista-leninista mobilizou, ao longo de uma década, centenas de militantes e activistas em todo o país e no exílio, recrutados principalmente junto da juventude estudantil e operária, assim como nos meios intelectuais, tendo, nas vésperas do 25 de Abril, dezenas de quadros nas prisões políticas do regime." J. M. L. Cordeiro, "Maoismo" in M. F. Mónica e A. Barreto, coord. Dicionário de História de Portugal, Lisboa, Figueirinhas, 1999: 417- 421.

10 - O MRPP (Movimentos Reorganizativo do Partido do Proletariado) foi um partido político de orientação marxista-leninista-maoista, fundado clandestinamente em Lisboa, em Setembro de 1970. Destacou-se pelo seu ativismo anticolonial, através de uma intensa campanha de propaganda e de manifestações de rua. Em 12 de Outubro de 1972, a Pide assassinou José António Ribeiro Santos, membro da organização estudantil do MRPP. Converteu-se em 1976 no Partido Comunista dos Trabalhadores Portugueses 
manifestações-relâmpago, publicavam comunicados e tarjetas e realizavam pinturas murais, sobretudo contra a repressão e a guerra colonial, em arriscados raids noturnos. O seu grau de exposição pública convocava admiração e propiciava o recrutamento de novos membros, conquanto ficasse assinalado por várias detenções $^{11}$. O movimento cooperativo livreiro, em que o MRPP interveio, permitiu a circulação de um conjunto de obras de literatura, de ciências sociais e, sobretudo, de política, aproveitando a conjuntura Marcelista e dilatando as malhas da censura.

No universo juvenil - de estudantes e de trabalhadores -, os últimos anos do Estado Novo ficaram marcados por uma dupla perda da hegemonia. Por parte do regime, que deixara de conseguir controlar instituições-chave, como a Faculdade de Direito, onde se formavam as elites dirigentes e se preparavam muitos dos seus filhos. Por parte da resistência habitual, com alguma ultrapassagem dos métodos cautelosos utilizados pelo Partido Comunista, que começaram a ser vistos como conciliadores.

A juventude assumira a nível mundial um novo e autónomo papel. No caso português, a universidade fora mudando ao longo da década de 1960, com a entrada de novas camadas sociais, em virtude do desenvolvimento do capitalismo português nesses anos. Jovens provindos de grupos sociais modestos acediam ao ensino técnico noturno nas fábricas da cintura industrial de Lisboa. Esta faixa etária, apartada pelas diferenças sociais, tinha a uni-la o espectro da guerra colonial, em que teriam obrigatoriamente de ir combater.

\section{Vidas sensíveis e resistência}

No relato de Aurora, as emoções são uma fonte de saber. Não seria possível de outro modo. Assim se apresenta, reportando ao Alentejo como terra de latifúndio e de luta, pautada por assimetrias sociais e marcada ao longo do séc. XX por constantes revoltas do proletariado rural:

“O meu nome é Aurora Rodrigues. (...) Tenho neste momento [2010] 58 anos. Sou alentejana (...)O meu pai, como era cantoneiro, ia muitas vezes a uma casa de ferramentas da Junta Autónoma de Estradas, na Rua do Poço Cavaco, em Castro Verde, levava-me com ele e ia-me contando estas

(PCTP-MRPP) e continua a participar nos atos eleitorais, com resultados escassos e sem representação parlamentar.

11 - O crescendo da organização é evidenciado pelo aumento do número de exemplares das edições do Luta Popular, cujo primeiro número sai em Fevereiro de 1971, bem como dos comunicados da organização e de outras conexas, como as que estavam associadas à luta anti-colonial: os CLAC's (Comités de Luta Anti-Colonial), o Movimento Popular Anti-Colonial (MPAC), ou a RPAC (Resistência Popular Anti-Colonial). 
histórias, pois o meu pai viu a guerra civil de Espanha de muito perto. (...) Chegou a estar preso numa cadeia espanhola, logo a seguir à guerra civil."

Longe do estrelato de que se cobrem as biografias de grandes políticos que resistiram à ditadura, Aurora enfatiza a trivialidade da sua vida, da sua luta e do seu contributo, enquanto «gente comum», título escolhido para a obra:

\begin{abstract}
"Acho importante contar o que me aconteceu, porque existe a ideia de que só eram presos e torturados grandes políticos, esquecendo-se que também 0 eram pessoas comuns, que era aquilo que eu era, sempre fui e ainda sou. Às vezes, leio aqueles livros sobre grandes figuras míticas que foram torturadas e não falaram, mas a verdade é que não foram só eles, muitas pessoas comuns que se opunham ao regime, por uma razão ou por outra, foram torturadas e conseguiram resistir e nisso não há nada de extraordinário. Outras pessoas não foram capazes de tomar este tipo de posições, ou porque não se sentiram apoiadas o suficiente ou por outro motivo."
\end{abstract}

Por um conjunto de acasos vários, conseguiu prosseguir estudos e obteve uma bolsa que Ihe permitiu ir estudar para a Faculdade de Direito de Lisboa. Era um dos lugares onde se reproduziam os grupos dominantes, uma faculdade hostil e classista, onde seria decisivo o contacto com o jovem Ribeiro Santos, estudante e militante do MRPP. Se este tinha uma voz maior do que o corpo franzino, e um poder retórico assinalável, era também alguém com sentido de humor, que jogava matraquilhos e circulava pelos locais de convívio estudantil da época, onde se concentravam os estudantes deslocados da província: as cantinas universitárias. Nesse final da ditadura, as formas de luta expressas tinham desencadeado um crescendo da repressão, com prisões e violência do regime sobre as manifestações, que culminaria num assassinato:

\footnotetext{
“No dia 12 de Outubro de 1972, assassinaram José António Ribeiro dos Santos em Económicas. (...) Eu estava ao pé dele, queria falar-lhe, saber o que ele tinha, como é que estava e ele, de repente, mudou de cor, ficou branco e ainda disse "depressa!". Foi então que foi levado para o hospital de Santa Maria. Penso que as pessoas não se aperceberam bem da gravidade, porque como inicialmente estava consciente, não se percebia que ia morrer. (...) Então levaram-no num carro para o hospital de Santa Maria e eu fui atrás, fui para a rua sozinha e apanhei um táxi. (...) Fui à procura dos médicos, estavam uns médicos sentados num grupo e eu dirigi-me a eles. (...) Veio um médico atrás de mim (...), e disse-me que ele tinha morrido."
}

A ênfase no assassinato pela PIDE-DGS do seu amigo e camarada Ribeiro dos Santos é central na história de vida de Aurora. Para muitos dos que viveram a repressão Salazarista e Marcelista, e que conviveram com a morte dum jovem amigo 
da sua idade, a memória está em carne viva, ainda que a tenham desejado banir ${ }^{12}$. As consequências de um acontecimento traumático exercem-se através duma rede de relações com efeitos estruturantes, sendo imprevisíveis na sua duração e no seu raio. O grau de exposição de Aurora Rodrigues aumentaria exponencialmente a partir desse acontecimento e fá-la-ia cair na mira da repressão, vindo a ser presa em 3 de Maio de $1973^{13}$. Ainda que, pelo seu testemunho, se tenha a perceção de que se evidenciou sobretudo no funeral de Ribeiro Santos, não escapara quatro meses antes ao interesse da PIDE-DGS, numa altura em que a Faculdade de Direito acabava de ser colocada sob o controlo dos «vigilantes», vulgo «gorilas» ${ }^{14}$.

\section{O sofrimento tangível e os escritos de prisão}

São vários os materiais, epistolares e fotográficos, que enquadram o espólio pessoal de Aurora Rodrigues. Num bloco de notas de papel quadriculado, já sem capa e com algumas folhas rasgadas, há um esboço de calendário que se inicia na contracapa, de cartão grosso. Serviu-lhe de orientação, impedindo o desnorte durante os quase três meses do tempo de prisão em que ficou isolada, confinada na área reduzida duma cela, sem relógio ou calendário. Ali alinhavou as marcações do tempo, as ideias, os planos. Era imperativo ter projetos, mesmo quando estava à mercê duma instância que a poderia manter arbitrariamente por um longo período. Escreveu os nomes dos meses em português, francês e inglês, redigiu um conto ingénuo, a "História do balão que subiu ao céu". Assim se certificava da sua sanidade mental e da sua memória, ao confirmar que não a destituíam do que aprendera nem a secavam por dentro, que a instituição total não lograva ocupar a esfera autónoma da sua resistência. Ao lado de um porco estilizado que esboçou nesse bloco, escreveu: "Um cão é um cão. Um gato é um gato. Um porco será sempre um porco". Numa outra página agenda a rotina da cadeia, com os ritmos do corpo e da vida celular por perfusão a sobreporem-se. Numa página, uma espécie de lâmpada, transmutada em

12 - A. Farge, “Qu'est-cequ'unévénement?", Terrain, n 38, Março, 2002, enfatiza que gerações inteiras podem ser acompanhadas por uma memória determinada, que marcará as respetivas posições éticas e as formas de cada um se aproximar do mundo. http://terrain.revues.org/1929.

13 - Na verdade, há muito que a polícia política a referenciara, logo a partir do liceu de Beja. Arquivo Nacional da Torre do Tombo, PI 4912, Arquivo da PIDE/DGS.

14 - O subchefe da PSP que prestava serviço na esquadra do Campo Grande testemunha que "Dos vinte e um estudantes capturados, a testemunha não os pode identificar pelos nomes, excepto um do sexo feminino que conhece bem por ser da sua terra. Chama-se AURORA RODRIGUES [maiúsculas a vermelho] e salientou-se bastante nesta altura pelas pedras que também atirou à Polícia." Arquivo Nacional da Torre do Tombo, Processo-Crime 231/73, Arquivo da PIDE/DGS, vol. 2, vs fl. 55. 
árvore; noutra, vários desenhos, "MAR O MAR OLHA", como num exercício de poesia visual.

\begin{abstract}
"O momento mais confuso para mim foi a entrada em Caxias, porque até aí estivera sempre acompanhada. Quando chego a Caxias, fico logo sozinha, e esse é que deve ter sido o momento de maior perturbação. Há um hiato na minha memória. Não sei exatamente quanto tempo passou desde que saí da carrinha até ter entrado na cela. Lembro-me de, antes de entrar na cela, à entrada do Reduto Norte, os guardas-prisionais me terem tirado os atacadores das botas, o relógio e o dinheiro. Consigo descrever perfeitamente essa primeira cela, porque depois mudei para outra só com dois beliches, que só tinha duas camas e aquela tinha quatro.(...) A prisão é um sítio muito fechado, mas numa cela daquelas ainda é mais. Tinha que decidir logo perante os guardas, de que naquela situação ninguém me veria a chorar ou de cabeça perdida, nunca me ouviriam a dizer palavrões, nem a insultá-los. Acho que era a única forma que tinha de me distanciar deles e de Ihes fazer sentir que eram torcionários."
\end{abstract}

A ação autónoma possível, dentro do horário prescrito pela entidade repressiva, está evidenciada na calendarização e nos planos que revela, num horário de estudo, pois era estudante de direito e estava presa durante um momento de exames. Previu uma estadia mais prolongada, durante a qual se propõe escrever "um conto simples" e "Depois, abalançar-me a um romance. Tenho tempo, não posso fazer mais nada."

Transmutar o que lhe aconteceu - a prisão, em que não age, mas operam sobre si, ficando à mercê de outrem - em algo que pode controlar e que escapa à esfera do que lhe é imposto, traduz a sua margem de liberdade, reforçando a perceção de que, mesmo encarcerada, não a vergam nem lhe corroem o espírito. Além da consciência política, para tanto contribui a rede social no exterior. Por exemplo, o seu pai, António Rodrigues, numa carta datada de 24 de Junho de 1973 escreve: "Recebemos as tuas cartas com datas de 18 e 20, como podes calcular trazem-nos sempre um embaciar de olhos que não podemos explicar se é alegria se é tristeza", adiantando depois que "Já tens os livros, estuda, os que te fizerem falta pede, mesmo com dificuldade se arranjarão, a nossa família parece desligada mas ao chegar a hora precisa tudo se uniu no mesmo objectivo, salvar-te, estuda a lei só livros úteis à sociedade, o mundo precisa de pureza e honestidade para que haja felicidade e alegria, não fazerem falta cadeias nem armas, vivermos sempre com a mesma pureza como nascemos".

O universo ideal, descrito pelo pai, era pouco compaginável com o momento de confinamento e a iminência da tortura. Usadas para obter declarações, que permitiam instruir os processos (depois julgados nos Tribunais Plenários) as sevícias assumiam vários formatos, fragilizando e despersonalizando os presos, apartando-os da sua rede social e desacreditando-os perante os seus camaradas. O isolamento, a "estátua», os afogamentos, os espancamentos, a privação do sono, as humilhações e a degradação 


\section{dos presos eram utilizados sucessivamente ou em combinação. Eram antecedidos de «avisos», cujo objetivo era amedrontar, ensimesmando a detida:}

\begin{abstract}
"Um dia, apareceram a dizer "Vais prestar declarações! Vais falar! Esta noite vais ouvir os cânticos vermelhos!". (...) "Está bem. Podem pôr, que eu já sei o que é. Põem gritos a sair ali daqueles vasinhos, são altifalantes, mas eu sei o que é, não me assusto".(...) Um dia, puseram-me em cima de uma cadeira e disseram-me assim: "Agora, ficas aí". Eu era muito levezinha, e como estava muito magra na altura, puseram-me de pé em cima da cadeira e agarraramme. Disse a mesma coisa: "Está bem. Enquanto vocês me agarrarem, eu fico aqui em cima. Quando me largarem, atiro-me daqui a baixo". Eles largaramme e desci da cadeira. De outras vezes, tiravam-me o banco em que me sentava, então punha-me a andar e dizia: "Está bem, tiram o banco, sento-me no chão". E sentava-me."
\end{abstract}

"Eles vinham, entravam, saíam e fizeram, logo no início, uma coisa horrível. Aliás, acho que na PIDE eles tinham formação em tortura e humilhação. $O$ que eles me fizeram foi encostar-me a uma parede - mas eram muitos, não eram só aqueles agentes que aparecem no processo - e começaram a fazer escarro ao alvo. Punham-se a escarrar a ver quem é que acertava. $\mathrm{O}$ alvo era eu."

"Ou foi para me manterem acordada ou porque disse uma vez a uma pide que não sabia nadar, o certo é que, a partir de certa altura, eles enchiam de água o lavatório, que estava na casa de banho e metiam-me a cabeça lá dentro. O lavatório não dava para meter a cabeça completamente, metiamme a cara, empurravam para baixo e eu ficava a sufocar."

"Foi uma coisa tão horrível, tão horrível, porque foi um espancamento a sério. Não há espancamentos a brincar, mas este foi sistemático. Não sei quanto tempo é que ele bateu. Ele batia com um cassetete e com joelhadas no músculo, do lado da perna, por cima do joelho e na cara batia com as mãos. (...) Não fiz nada e ia dizendo para dentro, nem sei se disse alto, mas para mim, dizia: "Isto vai acabar. Isto vai acabar". la sempre dizendo isto para mim, de pé, no meio da cela. Não cheguei a cair. Com os meus braços ao longo do corpo, ele ia-me batendo nas pernas e na cara, e bateu durante muito tempo. (...) Deu-me muitas pancadas. Bateu-me uma vez ou outra - mas não muito - no peito com o cassetete, mas bateu de forma sistemática nas pernas, no músculo ou tendão que fica no lado de fora por cima do joelho, que ainda tenho problemas aí. É uma dor muito forte, deve ser uma das partes do corpo mais sensíveis, só descobri dessa vez. (...) Estava assim parada e só era sacudida com o impulso das pancadas, porque estava quieta com as mãos nos bolsos e não me defendi, porque não tinha maneira de me defender. Também não me virei a ele, porque não tinha como. (...) Só acabou quando entraram dois indivíduos que o agarraram pelos braços um de cada lado e o arrastaram para fora da cela. (...) Depois daquele pide ter sido levado para fora da cela, não me cheguei a sentar. Senti uma impressão esquisita na barriga, não sabia se era vontade de defecar. Fui à casa de banho e verifiquei que tinha uma hemorragia, provocada pelo espancamento. Já não consegui levantar-me da sanita e tiveram de me levar em braços. (...) Quando passou o desmaio e recuperei a consciência, estava deitada no tal divã e ouvia-os a discutir, porque eles estavam com medo de me ter matado. Não sei quanto tempo estivedesmaiada, porque nunca ninguém me disse, mas ainda era de dia. (...) Eles não me mandaram embora. Continuaram a tortura nos mesmos moldes. Chegou o inspector e disse: "Estás a ver, desorientou-se, descontrolou-se", quando eles me tinham andado a dizer que vinham os índios. Ele disse que o outro se tinha descontrolado e que pertencia a uma brigada que usava outros métodos, que a dele não era assim, mas eu tinha que colaborar. (...) Levaram-me de novo para o interrogatório (...) Vou para o mesmo sítioe começam outra vez a interrogar-me: se eu era do MRPP, se continuava fiel à palavra deordem dopartido,quem é que estava comigo, tudo sempre muito incipiente Tudo continuou, com tortura do sono da mesma maneira." 
Através do bloco de papel quadriculado, tornou-se possível impedir que a passagem dos dias na cadeia pudesse ser medida só pelos ritmos do corpo e que o controlo do seu tempo ficasse estritamente delimitado pela esfera prisional. Assinala aí "450 horas de tortura de sono", bem como regista com tinta vermelha no calendário improvisado " $t$ " ou "tort" entre 23 de Maio e 7 de Junho e, de novo, entre 18 e 21 de Junho, indicando os períodos de tortura.

\begin{abstract}
"Quando a tortura do sono acabou, dessa primeira vez, ao fim de 16 dias inteiros, já não me segurava de pé. Além de me incharem e de sair um líquido das pernas e dos pés, tinha sentido como que uma espécie de barrete que ia descendo até a cabeça ficar insensibilizada e quando chegou aos olhos deixei de os conseguir abrir. (...) $\mathrm{Na}$ parte final, eu caía e para eles conseguirem que estivesse ali sentada, sem estar deitada no chão, nem cair, tinham que me agarrar. Como estava a ficar inconsciente e não conseguia mais abrir os olhos, que se fechavam, fizessem o que fizessem, levaram-me para o Reduto Norte, no dia 8 de Junho, de manhã. Apareceu outra vez o médico, que me perguntou se queria que ele me pusesse a soro e eu disse que não. E dormi. Não sei quanto tempo seguido dormi."
\end{abstract}

As visitas dos familiares, no círculo dilatado da família extensa, denotam a forma como se mobilizaram, neste momento de crise, os parentes e o núcleo de vizinhos, amigos e camaradas. A lista dos parentes que a visitam inclui doze pessoas: a mãe, o pai, a irmã, o cunhado, vários tios e tias (ARQUIVO NACIONAL DA TORRE DO TOMBO, 231/73). Não constam outros familiares e camaradas, que vinham até à cadeia, mas eram impedidos de entrar, por não serem parentes diretos. Rondavam pelas proximidades, sendo visíveis por Aurora a partir da janela da cela, no final dos encontros familiares. De modo subtil, ilegível para os carcereiros e para os agentes da polícia política, as visitas da família permitiam mensagens que alentavam.

\begin{abstract}
"Na primeira visita que tive, a minha mãe vinha com um lenço meu ao pescoço e uma carteira minha, daquelas da loja dos "Porfírios", para eu perceber que ela tinha as minhas coisas e que os pides não tinham localizado a minha casa. Ela não me podia dizer isso e então levava o lenço, a minha mãe, que nunca foi do estilo de usar lenço ao pescoço. Esteve toda a visita a falar normalmente e disse-me: "Olha, o pai está bem, estamos todos bem, eu estou calma, estás a ver?", e estendeu a mão, na direcção do vidro e a mão não tremia. Isto diante dos pides. Deve ter feito um esforço imenso. (...) Lá continuou a conversa e ao acabar a visita, mesmo antes de sair, a minha mãe, virou-se para mim e disse "Filha, porta-te bem. Não fales!"
\end{abstract}

Apesar da censura da correspondência, também as cartas da mãe, do pai, da irmã ou de uma tia permitiam alguma continuidade entre o universo prisional e o exterior. O pai escreve cartas em que se adivinha que se dirige mais do que à filha:

\footnotetext{
"Agradeço que me digas, porque motivo estás presa, na cadeia em que estás parece ser por política, será que tu andas metida nisso ou será por qualquer engano? Oxalá que sim, então tu em todos os estabelecimentos de
} 
ensino em que tens andado, tens sempre dado provas de aluna exemplar e nunca houve qualquer queixa de qualquer professor, o que para mim foi sempre uma honra, além de tantos sacrifícios, e agora saber que estás num lugar desses, sem eu ter a menor suspeita de coisas dessas, confessa-me tudo para me tranquilizares; és nova, e essas idades às vezes levam-nos a caminhos errados, mas qualquer erro se pode emendar e desde que seja emendado há perdão e a nossa vida não será prejudicada, espero que tenha sido algum engano ou confusão".

Todos os membros da família com quem se correspondia registavam as datas das cartas recebidas e enviadas. Assim, demonstravam controlar a periodicidade e as descontinuidades inerentes aos períodos de tortura, evidenciando grande inquietação quando não recebiam correspondência. Enquanto Aurora estava submetida a tortura, numa carta de 24 de maio de 1973, a mãe lamenta a falta de correspondência e remata de forma ambígua: "penso que terás tido novamente alguma coisa que te impeça de escrever, oxalá que não; Seja apenas porque tenhas pouco para dizer". Finaliza essa carta, como todas, convocando afetos duma rede doméstica, mas também extrafamiliar: "Muitos beijos e saudades de todas as pessoas amigas e vizinhas. Um grande abraço do pai e muitos beijinhos da tua mãezinha amiga".

Em 4 de Junho de 1973, os familiares de Aurora enviam um telegrama, dirigido ao Ministro do Interior e apenso ao seu processo no Arquivo da PIDE-DGS. Mostram a sua apreensão pela situação prisional e solicitam uma visita. Além destas iniciativas da própria família, patentes na correspondência que integra o espólio particular da Aurora, no Arquivo da PIDE/DGS encontra-se uma carta coletiva. É dirigida, em 7 de Junho de 1973, ao Conselho Escolar da Faculdade de Direito de Lisboa pelas "mães, pais, irmãos, tios e tias de vários estudantes da Faculdade de Direito de Lisboa, presos pela Direcção Geral de Segurança no passado dia 3 de Maio e seguintes. São eles: Aurora Rosa Salvador Rodrigues, Liliana S. José André, Marilia de Jesus Mendonça, José Alberto Lamego, José Luiz Saldanha Sanches, Pedro Bastos Teles Palhinha e Duarte.". Os familiares denunciam a dureza das condições prisionais e salientam a sua preocupação. No caso da Aurora, "a sua família está proibida de a ver há três semanas, temendo fortemente pelo seu estado de saúde". Aludem à privação do sono e enfatizam que a ausência de visitas faz temer o pior: "Desesperada, a sua mãe pediu que a deixassem escrever-Ihe, já que não sabia sequer se a sua filha estava viva ou morta. E disse que não saía de Caxias sem ter visto a sua filha, já que temia e tinha fortes suspeitas que algum mal Ihe tivesse sido feito. Em face desta atitude firme, um "polícia» ameaçou-a e insultou-a, dizendo-Ihe que "a bem ou a mal a $s r^{a}$ sairia dali". Num outro momento, escrevem que "Logo que chegaram a Caxias foram recebidos com insultos, com as metralhadoras aperradas e os "guardas 
prisionais» distribuíram ordens de prisão a torto e a direito, tendo prendido um dos acompanhantes da mãe da Aurora, que sentada num banco dizia não sair dali sem ver a sua filha" (ARQUIVO NACIONAL DA TORRE DO TOMBO, 2288/72).

Através das cartas da irmã, é levado até Caxias o quotidiano do jovem casal, que acaba de ser pai duma menina, a cujo batizado Aurora assistira pouco antes de ser presa. A irmã envia-lhe uma nova foto da sobrinha, segundo é anunciado numa carta de 12 de Junho pela mãe de Aurora e depois comentado noutras missivas. VaiIhe descrevendo o novo automóvel, «cor de café com leite», e a primeira papa da filha, ao mesmo tempo que cuida de Ihe arranjar um advogado e the envia selos. Uma das tias envia-lhe o papel selado necessário para passar uma procuração a um advogado conhecido da família.

Fora da cadeia, a rede de vizinhança e amizade mostrava-se operante, com as vizinhas a destinarem-Ihe mimos variados. Um vizinho alentejano, alfaiate de profissão e antigo preso político, enviou um doce tradicional e um par de calças que fez para ela. Numa carta de 13 de Junho de 1973, a mãe, Maria Amélia, diz ter mandado uma encomenda para que os tios Iha levem, "e na encomenda vão lembranças das nossas vizinhas que te mandam abraços.". Também o seu pai, António Rodrigues, escreve uma carta ao Presidente do Conselho, datada de 5 de Junho de 1973. Apresenta-se dizendo que tem 56 anos, que foi voluntário para a expedição aos Açores e que é cabo de cantoneiros da JAE, com 30 anos de serviço, sem repreensões no cadastro. Alega ter sempre votado na União Nacional - o que não fizera -, e que embora fosse "muitas vezes resmungão por este ou aquele motivo", se mostrara sempre cumpridor. Tem duas filhas que "com grande sacrifício meu, e auxílio de pessoas amigas, conseguiram fazer ambas o $5^{\circ}$ ano". Acrescenta que vê o futuro de Aurora prejudicado com esta prisão, enquanto a saúde dos progenitores está arruinada. Justifica a filha, declarando que com "21 anos não se passa de uma criança, embora já se pense que se é homem ou mulher".

Segundo os autos do processo instruído pela PIDE/DGS, Aurora recusou responder e assinar, sendo o auto autenticado só pelos agentes da DGS. Fora feita uma busca a casa dos tios de Aurora e, entre vários panfletos, haviam sido confiscados diversos livros que Ihe pertenciam, entre os quais, Imperialismo Estado Supremo do Capitalismo de Lenine, e Poesia I de José Gomes Ferreira. Aurora reiterou, no segundo auto, "Que se recusa a responder a toda e qualquer pergunta que Ihe venha a ser feita". Quando a questionaram sobre se o fazia "em cumprimento da palavra de ordem do MRPP", não respondeu. Manteve o mutismo quando lhe 
perguntaram se "como membro da FEM-L tem desenvolvido as suas tarefas". No terceiro auto, "volta a afirmar não prestar quaisquer declarações acerca das suas actividades, aconteça o que acontecer". Quando Ihe perguntaram se usava da palavra em meetings, e se incitava à desobediência, reitera "Que é evitado fazerem-Ihe mais qualquer pergunta, pois não responde a nenhuma." E mais não disse. "Lido este auto, o achou conforme, ratifica e não assina por se recusar a fazê-lo, indo ser assinado pelas testemunhas". Num quarto auto, afirmou "Que não presta quaisquer declarações a esta Direcção Geral". Quando Ihe são apresentados os panfletos e livros apreendidos, declarou "Que não esclarece a forma como os obteve"15. Foi libertada em Julho de 1973, sem vir a ser julgada, pois a PIDE-DGS não conseguira instruir o processo.

\section{Memórias sensíveis: o passado e o futuro são países estrangeiros?}

Nas sociedades ibéricas que sofreram com longos passados ditatoriais e com guerras, a passagem à democracia manteve lacrado e na obscuridade o combate dos vencidos e dos grupos sociais subalternos, remetidos para modalidades de ucronia ou para presentes alternativos. Num tempo de presentismos, a privatização da História conservou dentro dela o tempo cíclico, suscetível de assumir um formato comemorativo, patrimonializado e emblemático, paradoxalmente destinado ao instante organizado oficialmente e ao esquecimento. As perspetivas ucrónicas indiciam o que a vida poderia ter sido, sem algo que a perturbou. Os usos políticos da memória acerca dos passados ditatoriais expressam frequentemente o triunfo de uma versão consensual, enquadrando um passado utilizável. Para que as sociedades não sofram crises de identidade, a memória coletiva deve ser compatível com a identidade social definida no presente. Requer a atuação duma dupla influência, embora discreta, entre a memória coletiva dominante num dado período histórico e a historiografia produzida nesse mesmo período. Os vencedores não só fazem a história como a esquecem, deixando aos derrotados a meditação e imaginação acerca da possibilidade de os acontecimentos poderem ser diferentes. As memórias coletivas sensíveis, construtoras de sentidos de pertença, estão ligadas aos grupos, refletindo lugares sociais e

15 - Arquivo Nacional da Torre do Tombo, Processo-Crime 231/73, Arquivo da PIDE/DGS, vol. 2,fls 172. "Sendo-lhe referido que a citada propaganda é bem elucidativa da sua qualidade de membro da organização secreta, subversiva e revolucionaria, a que chamam MRPP, e que toda ela é um incitamento violento contra a defesa do Ultramar Português, que intitulam de "guerra colonial", preconizando a sua entrega incondicional aos "movimentos terroristas", Aurora terá retorquido que não responde, e recusa assinar. 
perspetivas diferenciadas. Mercê de conjunturas determinadas, algumas podem ultrapassar as dimensões do grupo e implantarem-se como memórias da sociedade. $\mathrm{Na}$ linha de Rancière, a partilha do sensível, essa inscrição da ordem do mundo nas categorias do visível e do dizível - o que se pode ver e o que é invisível, o se ouve ou é mero ruído -, é interditada quando se recusa a ordem da dominação, através da negação sensível de um mundo comum.

Aurora procurou os investigadores para contar. Tal como outros resistentes e vítimas que sofreram regimes ditatoriais e opressivos, corrobora a denúncia da violência e da opressão, exigindo uma reelaboração acerca dos processos de transição que envolva a memória da «gente comum» e da sua resistência. Escreve David Lowenthal que o passado é um artefacto do presente, um país estrangeiro, com evocações palpáveis e deliberadas. Ao acomodar-se nas versões dos grupos representados no poder, obscurece o combate dos que provêm de extratos sociais subordinados ou de grupos políticos minoritários, remetidos para modalidades de ucronia. Como lembra Josep Fontana, temos a tarefa de edificar um novo futuro, que lembre que as conquistas políticas, económicas e sociais conseguidas com as transições para a democracia não partiram de deuses ex machina, mas do sofrimento, alicerçado na sensibilidade e construção comum dos resistentes. Para que o novo futuro não seja igualmente um país estrangeiro ${ }^{16}$.

\section{Referências Bibliográficas}

ARQUIVO NACIONAL DA TORRE DO TOMBO, Processo-Crime 231/73, Arquivo da PIDE/DGS, IV Vol., vs. fl. 238.

ARQUIVO NACIONAL DA TORRE DO TOMBO, Proc.2288/72 SR, Arquivo da PIDE/DGS.

GODINHO, P. Memórias da Resistência Rural no Sul - Couço, 1958-1962, Oeiras, Celta, 2001.

GODINHO, P. "Introdução - História de um testemunho, com Caxias em fundo", in A. Rodrigues, Gente Comum - Uma história na PIDE, Castro Verde, 100 Luz, 2011: 2022.

HARTOG, F.Régimes d'Historicité - PrésentismeetExpériencesduTemps, Paris, Seuil, 2003;

16 - D. Lowenthal, The Past is a Foreign Country, Cambridge, CUP, 1985; J. Fontana El futuroes un paísextraño. Una reflexión sobre la crisis social de comienzos del siglo XXI. Barcelona: Ediciones de Pasado y Presente, 2013; A. Portelli, "Uchronic dreams: working class memory and possible worlds", Oral History, vol. 16, Outono, 1988:46-56. 
HARTOG, F. Croire en l'Histoire, Paris, Flammarion, 2013.

RANCIĖRE, J. Le partage du sensible. Esthétiqueet politique, Paris, La fabrique, 2000

RODRIGUES, Aurora, Gente Comum - Uma história na PIDE, Castro Verde, 100 Luz, 2011.

SCOTT, J. C. Weapons of the weak - Everyday Forms of Peasant Resistance, New Haven and London, Yale University Press, 1985,

SCOTT, J. C. Domination and the arts of Resistance- Hidden Transcripts, New Haven and London, Yale University Press, 1990. 